\title{
IMPLICAÇÕES EMOCIONAIS NA PARTICIPAÇÃO POLÍTICA DE DIRIGENTES DO PSDB/ES
}

IMPLICACIONES EMOCIONALES EN LA PARTICIPACIÓN POLÍTICA DE LOS LÍDERES DEL PSDB/ES

EMOTIONAL IMPLICATIONS IN THE POLITICAL PARTICIPATION OF PSDB/ES LEADERS

http://dx.doi.org/10.1590/1807-03102015v27n3p640

Everton Faria Meira, Márcia Prezotti Palassi, Alfredo Rodrigues Leite da Silva e Letícia Dias Fantinel Universidade Federal do Espírito Santo, Vitória/ES, Brasil

\section{RESUMO}

Este artigo visa a compreender a dinâmica das emoções que envolvem a participação política de dirigentes do Partido da Social Democracia Brasileira/PSDB no Espírito Santo. Adota-se uma abordagem históricocultural, associada à discussão sobre participação política e partidos políticos. Trata-se de um estudo de caso de natureza qualitativa baseado na epistemologia qualitativa de Gonzalez Rey (2005). Os dados foram obtidos entre abril/2011 e março/2013, através de questionário, redação, observação participante, conversações grupais e individuais com quatro dirigentes do PSDB em Vitória/ES. Os resultados revelam que a tristeza e decepção dos sujeitos com o PSDB ajudam a reduzir a intensidade da participação política no partido, produzindo elementos subjetivos em tensão com alguns sentimentos. As considerações finais discutem o contexto político brasileiro e indicam a necessidade de modificar os processos internos de tomada de decisão, bem como a estrutura partidária de um modo geral.

Palavras-chave: emoções; PSDB; participação política; partidos.

\section{RESUMEN}

Este artículo tiene como objetivo comprender la dinámica de las emociones que implican la participación política de los dirigentes del Partido da Social Democracia Brasileira/PSDB en Espírito Santo. Adopta el enfoque histórico-cultural, combinado con la discusión de la participación política y los partidos políticos. Es un estudio de caso cualitativo basado en la epistemología cualitativa de González Rey (2005). Los datos fueron recogidos entre abril/2011 y marzo/2013 a través de cuestionario, escritura, observación participante, conversaciones individuales y de grupo con los cuatro líderes del PSDB en Vitória/ES. Los resultados muestran que la tristeza y la decepción de los sujetos con el PSDB ayudan a reducir la intensidad de la participación política en el partido, productor de elementos subjetivos en tensión con algunos sentimientos. Las consideraciones finales discuten el contexto político brasileño y indican la necesidad de cambiar los procesos internos de toma de decisiones, y la estructura del partido en general.

Palabras clave: emociones; PSDB; participación política; partidos.

\begin{abstract}
This article aims to understand the dynamics of emotions involving the participation of political leaders of the Partido da Social Democracia Brasileira - PSDB/ES. The study adopts a cultural-historical approach, associated with a discussion of political participation and political parties. Data were collected between april/2011 and march/2013 taking as subjects of investigation four party leaders of PSDB in Vitória/ES. The data was analyzed in accordance with the methodology proposed by González Rey (2005). Results reveal that the feeling of sadness and disappointment from those associated to PSDB reduces the intensity of political participation in the party, producing subjective elements in tension with some feelings. In the concluding section, Brazilian political context is approached. The emergent discussion indicates the need to modify the internal processes of decision making and party structure in general.
\end{abstract}

Keywords: emotions; PSDB; political participation; political parties. 


\section{Introdução}

O objetivo deste artigo é compreender a dinâmica das emoções que envolvem a participação política de dirigentes do PSDB/ES. O interesse pela compreensão desta dinâmica emergiu a partir da vivência de um dos autores do presente artigo junto aos partidos políticos, inicialmente como dirigente do movimento estudantil e posteriormente como assessor de um parlamentar filiado ao PSDB/ES. Percebeu-se, a partir de tal vivência, que, nesse contexto, as decisões eram centralizadas em nível de executiva e que havia membros do diretório estadual que não se sentiam dirigentes partidários. Assim, para a articulação do objetivo aqui propugnado, parte-se do pressuposto que a construção da participação política configurase como um processo permanente, influenciado pela relação dialética entre as emoções e os processos simbólicos das pessoas que participam (González Rey, 2003; 2004; 2005). Os partidos políticos, cenário desta participação, possuem papéis fundamentais em um sistema político competitivo, quais sejam: contribuir para formar a opinião pública, configurar a cultura política, selecionar os candidatos ao poder, enquadrar os eleitos, canalizar e fomentar as demandas e agregar interesses diversos (Ibañez \& Iñiguez, 1996).

Nesse sentido, cabe problematizar a participação em partidos políticos, especialmente na contemporaneidade, em que se constata a procura crescente por canais alternativos de participação (Alves \& Viscarra, 2012; Castro \& Reis, 2012; Norris, 2011). Atualmente, fala-se em um distanciamento entre a proposta e a prática dos partidos políticos (Braga, 2008), bem como em uma falta de ajustamento de seu papel na atual democracia (Lamounier, 1992; 1994; Lima, 1993; Meneguello, 1996), gerando o que se chama de uma crise de representação (Braga, 2008).

Para a compreensão dos desdobramentos de tal participação no âmbito subjetivo, adota-se, neste artigo, uma abordagem que enfoca as implicações emocionais desses participantes. Segundo González Rey (2003; 2004; 2005), as pessoas compartilham estados emocionais de modo complexo, fenômeno que torna o social um tecido simbólico-emocional dentro do qual as suas emoções e ações aparecem interrelacionadas de diferentes formas. Ao concordar com esse entendimento e adotá-lo para tratar da temática da participação política, no presente artigo tem-se como problema de pesquisa a seguinte questão: como a dinâmica das emoções envolve a participação política de dirigentes do PSDB/ES?

No intuito de responder à referida pergunta, foi realizado um estudo de caso de natureza qualitativa baseado na epistemologia qualitativa de Gonzalez Rey (2005), cujos dados foram obtidos entre abril de 2011 e março de 2013. Como técnica de coleta de dados, fez-se uso de questionário, redação e diário de campo, além de conversações individuais e grupais com os sujeitos. Os dados empíricos foram confrontados com o quadro teórico selecionado ao longo do processo de pesquisa, tais como: emoções na perspectiva históricocultural (Gomes \& Mello, 2010; Pereira, Barros \& Augusto, 2011; Vigotski, 1971; 2004); participação política (Andaluiza \& Bosch, 2009; Sabucedo, 1996; Verba \& Nie, 1987); e partidos políticos (Castro \& Reis, 2012; Duverger, 1963; Ibañez \& Iñiguez, 1996; Michels, 1949).

Portanto, este artigo encontra-se estruturado da seguinte maneira: primeiramente, apresentam-se os conceitos centrais na visão dos autores que compõem o quadro teórico adotado; em seguida, expõem-se os aspectos metodológicos que nortearam a pesquisa empírica; após esta fase, realiza-se uma discussão sobre a experiência da participação política enfatizando as emoções produzidas em tal processo, em que se analisam os dados empíricos à luz do quadro teórico, para, finalmente, explicitarem-se as considerações finais.

\section{As emoções na perspectiva histórico-cultural}

A busca por uma explicação da natureza e da forma como surgem as emoções, no conjunto das funções psíquicas (inteligência, avaliações, memória, etc.) das pessoas, é tratada neste artigo por meio de categorias próprias da abordagem histórico-cultural de González Rey $(2003$; 2004) e de Vigotski (1971; 2004), que busca superar contradições da Psicologia tradicional.

Ao defender a unidade entre aspectos emocionais e a cognição, Vigotski (2004) elaborou sua crítica à Psicologia Explicativa e à Teoria Periférica associada a uma compreensão organicista, concepções amplamente aceitas na primeira metade do século XX. A crítica à Psicologia Explicativa fundamenta-se na impossibilidade de se estabelecer um nexo entre as emoções e outras dimensões da vida psíquica das pessoas.

A crítica à Teoria Periférica fundamenta-se na visão de que as emoções consistiriam em processos restritos ao funcionamento do organismo das pessoas e que estariam localizadas, de maneira central, resultando da atividade e da interação do córtex com o tálamo. Para o autor, os aspectos psíquicos e somáticos, apesar 
de serem independentes e poderem ser provocados separadamente, possuem uma estreita conexão com aquilo que foi chamado de "afeto íntegro" (Vigotski, 2004 , p. 134) e o desenvolvimento de um aspecto poderia não só facilitar o desenvolvimento do outro, mas até mesmo reforçá-lo. Dessa maneira, as emoções não apareceriam apenas manifestas nas mudanças orgânicas, mas possuiriam significação nas ações dos sujeitos.

Segundo este ponto de vista, estreitamente vinculado ao contexto sócio-histórico-cultural, as emoções passaram a ser compreendidas como processos que evoluem, e que possuem aspectos biológicos, mas não se limitam a eles.

Vigotski oferece uma explicação dos fenômenos e processos a partir de sua história e interdependência $\mathrm{e}$, coerente com a matriz dialética que fundamenta sua teoria, considera que as emoções sofrem mudanças qualitativas à medida que o sujeito avança no desenvolvimento das demais funções psíquicas. (Gomes \& Mello, 2010, p. 681)

A obra de Vigotski (2004) relaciona a emoção com categorias como necessidade, motivos e personalidade e considera que a condição simbólica não é suficiente para desencadear a emoção. Nesta linha, González Rey (2003, p. 245) defende que “ toda atividade ou relação implica o surgimento de um conjunto de necessidades para ter sentido para o sujeito" no contexto da realização dessa ação.

Segundo tal perspectiva, os processos até então considerados objetivados passam a ser analisados sob uma nova compreensão, com um foco históricocultural. A posição de Pereira, Barros, e Augusto (2011), por exemplo, está baseada na premissa de que, nos momentos em que as pessoas constroem suas relações com as outras, as emoções fazem emergir formas especiais de conexão e de movimento, novas produções em relação à experiência vivida, o que reafirma o caráter gerador da subjetividade humana.

Portanto, na perspectiva histórico-cultural adotada neste artigo, a emoção é considerada uma produção imbricada na constituição social da subjetividade e condição permanente na definição de um sujeito que se expressa a partir desse estado emocional (o sujeito da emoção). O sujeito perde seu caráter objetivo, já que ele produz emoções singulares de acordo com a experiência vivida. É por isso que, conforme Vigotski (1971), nossas reações ficam mais lentas e perdem intensidade, assim que o elemento central da emoção torna-se mais complexo, uma vez que a emoção define a ação do sujeito.

Com base nessa relação entre a intensidade e a complexidade da emoção, no presente artigo, as emoções são tratadas como "mais complexas" e "menos complexas", diferentemente da valoração comumente estabelecida de que as emoções são positivas ou negativas. Partindo-se desse entendimento, defendese que é possível compreender adequadamente a dinâmica que envolve a produção de emoções e suas influências em determinados conjuntos de ações dos sujeitos. Entre essas ações estão as que articulam a participação política, foco deste artigo.

\section{A participação política, suas contradições e consequências}

A participação política compõe-se de "qualquer ação dos cidadãos dirigida a influenciar o processo político e seus resultados" (Andaluiza \& Bosch, 2009 , p. 26, tradução nossa). Essa definição mais ampla deve considerar aspectos específicos, como a tomada de decisões, dentre outros elementos que demarcam o contexto político. Tal perspectiva é defendida por Sabucedo (1996, p. 89), ao definir a participação política como "ações intencionais, legais ou não, desenvolvidas por indivíduos ou grupos com o objetivo de apoiar ou questionar qualquer dos distintos elementos que configuram o âmbito do político: tomada de decisões, autoridades e estruturas". Verba \& Nie (1987, p. 2, tradução nossa) reforçam a importância de se considerar a tomada de decisões e o foco nas autoridades ao destacarem o papel da participação política em "influenciar a seleção de pessoal de governo e/ou as ações que eles tomam".

Vale ressaltar que não é possível apresentar um único conceito universal que dê conta de definir a participação política em todas as suas manifestações. Por isso, para fins deste artigo, a participação política é considerada um processo subjetivo que implica configurações diversas da subjetividade humana, que não dizem respeito somente à política, tendo em vista que a própria política é, por si, uma produção subjetiva. Aspectos individuais como necessidade, motivos e personalidade podem ser inseridos no debate, pois estão diretamente implicados na participação política ou no contex to de realização de qualquer ação humana.

Por sua vez, essa vivência insere na participação política as inseparáveis atitudes (Vigotski, 2004) inerentes. A avaliação dos sujeitos acerca do sistema político depende dos sentimentos e emoções produzidos, aspectos que operam em estreita relação com o conhecimento construído por esses sujeitos sobre o próprio sistema. A memória e a vontade são também determinantes na formação das atitudes no processo político, que incluem as relações entre a 
participação política mais comprometida e um maior nível de politização dos sujeitos, bem como um maior vínculo entre o sujeito que participa politicamente e seus pares.

Sabucedo (1996) voltou-se para a discussão sobre o que leva o sujeito a se envolver, de diferentes maneiras, na participação política. $\mathrm{O}$ autor considera que o sujeito produz sua participação política a partir de sua intencionalidade, tratando, portanto, a intenção do sujeito como uma variável que indicaria esta participação.

Andaluiza \& Bosch (2009) identificaram uma série de fatores, de cunho individual e social, que estariam relacionados à participação política: idade, nível de escolaridade, renda, ocupação e tempo disponível, redes sociais, grupos e organizações, contexto político e institucional, interesse e compromisso com a política. Conforme os referidos autores, a participação política é afetada pelas atitudes, que são orientações adquiridas, relativamente estáveis, e dirigidas a objetos políticos, que possuem diferentes intensidades para cada sujeito. As atitudes podem ser classificadas em três tipos diferentes:

atitudes cognitivas (relativas ao conhecimento dos distintos elementos do sistema político), afetivas (relativas aos sentimentos e emoções que se dirigem a esses elementos) e valorativas (relativas à avaliação que o indivíduo faz dos distintos elementos do sistema). (Andaluiza \& Bosch, 2009, p. 47, tradução nossa)

No entendimento de Vigotski (2004), a diferenciação teórica entre atitudes, segundo as diversas funções cognitivas, não faria sentido, pois tais funções encontram-se integradas no cérebro humano. Assumese que a complexidade do fenômeno político nos sujeitos depende não só do conhecimento construído sobre eles, mas também dos sentimentos e emoções produzidos em estreita relação com o conhecimento e a avaliação que se faz desse sistema. O surgimento de cidadãos desconfiados do sistema político, por exemplo, relaciona-se com cidadãos mais críticos (Norris, 2011), e esta desconfiança com o sistema político de modo geral vem provocando mudanças nos canais e nas formas de participação política (Alves \& Viscarra, 2012; Castro \& Reis, 2012).

Em um esforço para delimitar as consequências dessa participação política, Andaluiza \& Bosch (2009) as tipificam em três vertentes básicas: (a) as consequências para o sujeito, (b) as consequências para a política, e (c) as consequências para a democracia. Destaca-se neste artigo a primeira vertente, as consequências da participação política para o sujeito, com foco na sua atuação nos partidos políticos amplamente estudados na literatura, cujos principais aspectos são apresentados a seguir.

\section{Os partidos políticos como contexto historicamente situado}

Os partidos políticos são instituições relevantes na dinâmica de regimes democráticos (Paiva, Braga, \& Pimentel, 2007), na medida em que são necessários para a promoção da participação democrática (Testi, 2000). Eles possuem papéis essenciais em sistemas políticos competitivos, quais sejam: contribuir para formar a opinião pública, configurar a cultura política, selecionar os candidatos ao poder, enquadrar os eleitos, canalizar e fomentar as demandas e agregar interesses múltiplos (Ibañez \& Iñiguez, 1996).

O confronto dado no âmbito das arenas políticas envolve questões a serem mediadas e resolvidas pelos diversos processos presentes em um regime democrático, o que evidencia a importância dos partidos (Elster, 1998). Na visão de Ibañez \& Iñiguez (1996), contudo, o funcionamento dos partidos políticos cada vez mais se encontra marcado por uma necessidade de participação exitosa em diferentes disputas eleitorais, diferindo de propósitos iniciais, como o de representar distintas forças sociais presentes na sociedade. Assim, o que se vê contemporaneamente é que a participação das pessoas não é condição necessária para a vitória eleitoral dos partidos (Russell, 2007).

Dentro desse debate sobre a participação política, Michels (1949) defende a tendência de que agrupamentos políticos, mesmo os emersos sobre bases democráticas, transformam-se em férreas oligarquias. Ao analisar o Partido Socialdemocrata Alemão, o autor questiona a possibilidade de existir democracia interna em organizações partidárias complexas. Para ele, sempre valerá a chamada "Lei de Ferro das Oligarquias", que representa uma forte tendência à centralização das decisões partidárias.

Duverger (1963), por sua vez, constata uma clara distinção entre partidos de quadros e de massas: partidos de quadros seriam os partidos mais antigos e tradicionais, caracterizados principalmente por tomar suas decisões mais importantes em petit comité (pequenos comitês), enquanto os partidos de massa tomam suas decisões em fóruns mais amplos, e teriam surgido a partir da expansão do sindicalismo e crescido com a força da militância. Duverger (1963), que nutria profunda admiração pelo Partido Socialista, via no partido uma maneira de combater o acentuado autoritarismo dos dirigentes sindicais. Assim, o autor 
destaca os mecanismos internos que permitiriam aos partidos políticos uma atuação mais democrática.

Com foco no contexto brasileiro, Alves e Viscarra (2012) constatam que, assim como em parte da América Latina, os partidos políticos no Brasil vêm sofrendo de um profundo descrédito por parte da população, levando as pessoas à escolha de outros canais de participação política. Castro e Reis (2012, p. 21) também compartilham dessa opinião, apontando que:

o Brasil faz parte deste quadro latino-americano. Suas instituições políticas são consideradas ineficazes, corruptas e assistencialistas, o que propicia a emergência de canais de participação não relacionados à sociedade política como formas de transmissão de demandas.

Parte de tal descrédito pode ser atribuída ao fato de que existe um distanciamento entre o que os partidos políticos se propõem a ser e aquilo que eles são (Braga, 2008). Alguns autores caracterizam essas organizações como frágeis, e mostram-se críticos acerca da construção de partidos que cumpram melhor sua função na atual democracia, por conta do individualismo e do caráter personalista da organização partidária brasileira (Lamounier, 1992, 1994; Lima, 1993; Meneguello, 1996).

Tais críticas exigem uma reflexão sobre o interesse na participação política por meio dos partidos. Por isso, ao buscar-se a compreensão da dinâmica das emoções envolvidas na participação política, é possível refletir sobre o próprio fenômeno político, a partir de confrontos entre as contribuições teóricas articuladas até aqui e as evidências empíricas obtidas no campo. Assim sendo, o estudo adotou uma metodologia que permitisse a expressão das emoções de dirigentes partidários, a qual será exibida a seguir.

\section{Aspectos metodológicos do estudo}

A pesquisa adotou uma abordagem qualitativa, fundamentada na epistemologia qualitativa proposta por González Rey (2003, 2004, 2005), que teve início com a vivência de um dos autores deste artigo junto a dirigentes e militantes do PSDB/ES, iniciada em abril de 2011 e que se estendeu até março de 2013, período durante o qual o pesquisador registrou suas observações em um diário de campo. Ao longo desse período, criouse o cenário de pesquisa (González Rey, 2005), espaço social que caracteriza o desenvolvimento da pesquisa e que está orientado a promover o envolvimento dos participantes. Em conjunto com a vivência, o cenário de pesquisa foi criado com o envio de um e-mail contendo os seguintes itens: informações sobre a pesquisa, questionário aberto contendo perguntas acerca da vida partidária e pessoal e o pedido de uma redação com o tema "Por que sou militante do PSDB?", na qual o sujeito poderia escrever livremente sobre o tema. $\mathrm{O} e$-mail foi enviado às 75 pessoas consideradas dirigentes do PSDB/ES (membros titulares e suplentes do diretório estadual, bem como do conselho fiscal e do conselho de ética).

Quatro pessoas responderam o e-mail completamente, sem a necessidade de outros estímulos, expressando o desejo de falar a respeito da sua participação política no PSDB/ES, constituindo-se no grupo de sujeitos da pesquisa. Foram três homens e uma mulher, sendo os homens com idade entre 58 e 67 anos, e a mulher com 24 anos. Dois homens estavam filiados ao partido há doze anos, o outro há dezoito anos e a mulher há três anos. Os três homens foram criados no meio urbano, enquanto a mulher tem sua origem no interior do Espírito Santo. Assim, a investigação empírica se desenvolveu a partir dos indicadores de sentidos subjetivos obtidos nesta primeira etapa da pesquisa.

Neste material inicial foram observadas expressões motivadas por distintas emoções, discutidas na análise dos dados. Os indicadores obtidos possuíam relação com o tempo de filiação, a família, os cargos exercidos, os referenciais de esquerda e de direita, a avaliação dos colegas tucanos ${ }^{1}, o$ fracasso do governo de José Ignácio Ferreira no Espírito Santo², o PSDB e o futuro. Em conjunto, o questionário, a redação e o diário de campo auxiliaram a evidenciar emoções que adquiriram significado quando foram comparadas com emoções que emergiram nos momentos empíricos posteriores, caracterizados pela dinâmica conversacional. Na dinâmica conversacional (González Rey, 2005), o pesquisador precisa deslocarse do lugar central das perguntas para se integrar a ela.

Sendo assim, foi feita uma conversação individual com cada sujeito, na qual foi solicitado que contextualizasse sua filiação ao PSDB em relação ao momento de sua vida na época da filiação. Em seguida, foram realizadas três conversações grupais, já que o trabalho em grupo produz maior quantidade de trechos diferenciados de informação (González Rey, 2005). Na primeira reunião em grupo, discutiuse a participação política de cada um dos sujeitos no $\mathrm{PSDB} / \mathrm{ES}$, com foco nos problemas que o partido enfrentava na atualidade. $\mathrm{Na}$ segunda conversação grupal, debateu-se a participação política de cada um dos sujeitos, cujo foco era a trajetória que cada um construiu no partido. Na terceira conversação em grupo, as hipóteses formuladas nas etapas anteriores 
foram apresentadas pelo pesquisador, a fim de permitir a análise e a expressão dos envolvidos na pesquisa sobre o que havia sido discutido até aquele momento.

Vale esclarecer que na metodologia adotada as hipóteses não possuem significação estatística. Elas consistem em pequenos textos que constituem a base de um conhecimento em construção (González Rey, 2005). Tais hipóteses foram obtidas com base na constante revisão dos relatos dos sujeitos e na comparação com informações obtidas através dos diversos instrumentos. As hipóteses, organizadas, constituem o modelo teórico apresentado a seguir. Este modelo teórico não busca esgotar o problema estudado, mas abrir novas zonas de inteligibilidade que permitam uma aproximação diferenciada sobre o problema. Para González Rey (2005), o processo de construção da teoria é um processo vivo, onde o pesquisador é o núcleo gerador de pensamento e parte inseparável do curso da pesquisa. Segundo González Rey (2005), o pesquisador carrega um repertório de representações e sentidos subjetivos que frequentemente expressam uma memória teórica que é como um princípio de valor heurístico para a construção da experiência.

Conforme a metodologia proposta por González Rey (2005), o pensamento do pesquisador é a única via legítima de produção de modelos de inteligibilidade. Não é possível aplicar aos trechos de informação um conjunto de conhecimentos preestabelecidos para significá-los como categorias preestabelecidas ou $a$ priori. Nesta metodologia, o pesquisador constrói os resultados progressivamente, de acordo com a sua reflexão teórica, em um processo construtivointerpretativo do conhecimento sobre as emoções dos sujeitos. A seguir, são apresentados os resultados da pesquisa, cujos nomes dos sujeitos da pesquisa são fictícios para preservar a identidade deles.

\section{Emoções, percepções e memória na experiência política}

As informações oriundas dos momentos empíricos da pesquisa foram separadas em duas unidades de análise: "Descrédito em relação ao sistema político" e "Orgulho da participação política". Esta separação não é estanque. Pelo contrário, o descrédito em relação ao sistema político e o orgulho em assumir a participação política são dois importantes indicadores da emocionalidade subjacente à participação política e que se imbricam em sua dinâmica. A dinâmica das emoções que emergiram a partir da participação de sujeitos em um partido político integra, como exibido anteriormente, distintas funções psíquicas (Vigotski, 1971; 2004), por exemplo, a memória, a vontade, o conhecimento e a avaliação que se faz dos distintos elementos da política.

\section{Descrédito em relação ao sistema político}

O relato de Juliana ilustra essa integração, com base em sua experiência de participação política, onde a mesma adquire o significado de enfrentamento ao grupo que comanda a juventude do PSDB/ES.

$\mathrm{Na}$ primeira conversação em grupo, ao ser questionada se estava feliz na juventude, ela respondeu que sim, mas emendou: "vamos ver, né? Vai ter eleição aí, ano que vem [2014]. Vamos ver se a gente consegue mudar. Mudar não, no caso, fazer a juventude de Vitória, que tem tempo que não tem [juventude organizada no PSDB do município de Vitória]". Em outro momento da mesma conversação, Juliana voltou a expor problemas da juventude do PSDB: “A juventude tem o presidente, não é ativo. É a vice. Aí o presidente saiu, a vice assumiu. Ela foi e chamou, convocou a eleição, a presidente de Vitória. Ele [o presidente que saiu] foi e impugnou a eleição. Tava a maioria da juventude lá pra votar".

Nesses excertos, observa-se o desejo de mudança na direção da juventude do partido. Para Vigotski (2004), a vivência insere na participação política as inseparáveis atitudes entre diferentes funções psíquicas do sujeito. Assim, o desejo de mudança parece motivar sua participação política no partido, construindo novas atitudes. Na conversação individual, Juliana já apresentava os primeiros indicadores do papel que assume no partido: "nunca vai existir um partido 100\% limpo, porque partido é feito de pessoas e as pessoas erram. Aí cabe ao partido punir e tentar excluir esse tipo de pessoa". A presença de Juliana no Conselho de Ética do PSDB/ES, nesse caso, pode ter influenciado sua visão sobre o papel do partido diante dos desvios de conduta de seus filiados.

O afastamento dessas pessoas na forma de punição evoca o sentimento de justiça. Desse modo, é possível notar como a complexidade do fenômeno político nos sujeitos depende não só do conhecimento construído sobre o fenômeno, mas também da integração dos sentimentos e emoções produzidos, da memória e da vontade (Vigotski, 1971, 2004). O relato de outro sujeito da pesquisa, Guilherme, também ilustra tal integração, na medida em que ele avalia suas experiências políticas atuais e pregressas, com base em uma visão de mundo construída socialmente e partilhada com outros sujeitos:

eu li o recado que Fernando Henrique deu outro dia, que é quem eu tenho uma admiração muito grande 
porque ele fez um governo, fez um projeto, que infelizmente não teve um sucessor, e o Lula navegou em cima do que ele fez e tá acabando com tudo.

O relato do sujeito pesquisado pode ser interpretado como a expressão de emoções produzidas a partir de sua experiência subjetiva, influenciada por sua memória em relação a experiências pregressas e por sua percepção no que diz respeito ao governo de dois ex-presidentes brasileiros: o primeiro, representante do PSDB; e o segundo, de outro partido, tradicionalmente seu rival na arena política, o Partido dos Trabalhadores - PT. Neste ponto é reafirmado o caráter personalista da organização partidária brasileira (Lamounier, 1992, 1994; Lima, 1993; Meneguello, 1996), e como a percepção sobre o passado político influencia emoções e atitudes expressas pelo sujeito na conversação. $\mathrm{Na}$ segunda conversação grupal, Guilherme afirma:

Esses blogs todos. Eu tenho os blogs da esquerda e os da direita. Eu leio todos. Leio Veja, tem uns que são razoáveis, tem uns que são muito radicais. Alguns que são realmente, parecem compromissados com algum esquema, tem outros que ... Lá tem de tudo.

O respondente afirma ler $b \log s$, e as notas de campo sobre a vivência com Guilherme permitem afirmar que ele participa de redes sociais e grupos de discussão na internet. Essa busca por outros canais de participação política (Alves \& Viscarra, 2012; Castro \& Reis, 2012; Norris, 2011) foi sua alternativa para continuar participando da vida política do país. Tal atitude está em sintonia com o pensamento de Alves e Viscarra (2012), que destacam haver um número cada vez maior de pessoas que participam politicamente de canais não relacionados diretamente à chamada política dita convencional. $\mathrm{O}$ descrédito quanto à política é um sentimento, em geral, produzido a partir tanto do passado político (Castro \& Reis, 2012), quanto de experiências pregressas e presentes. No caso de Guilherme, como se verifica no trecho de uma conversação individual reproduzida a seguir, experiências anteriores vividas por ele serviram para tornar mais complexo o elemento central de suas emoções em relação ao grupo político presente no PSDB, provocando uma redução na intensidade de sua participação política.

Pra mim, ... a eleição do Luiz Paulo foi o ponto definitivo pra eu saber quem é essa turma. Gosto do Luiz Paulo, gosto do Emanuel [vereador eleito em 2012 e ex-presidente do PSDB de Vitória], gosto deles todos como pessoa, seremos sempre amigos, mas politicamente...

A interrupção da frase demonstra que algum desgosto vivido por Guilherme durante a campanha de Luiz Paulo Vellozo Lucas, candidato derrotado a prefeito de Vitória pelo PSDB na eleição de 2012, trouxe consequências para a sua participação política, sugerindo sua intenção em parar de participar no PSDB. Mas a tentativa de Guilherme de separar suas relações pessoais de suas relações políticas relacionase com os distintos papéis que os sujeitos encarnam em diferentes contextos por onde eles transitam (González Rey, 2003). De maneira similar ao caso de Guilherme, os desgostos vividos por Miguel ao longo de sua vida partidária também provocaram uma redução na intensidade de sua participação política. Isso se evidencia no fragmento de um de seus relatos a seguir, no qual a honestidade aparece como um elemento central de suas emoções em relação ao partido:

o PSDB se deixou infiltrar aí por ... bom, a gente teve o caso da Yeda Crusius lá no Rio Grande do $\mathrm{Sul}^{3}$ que foi bastante emblemático, né? E também quando o partido começa a defender coisas que não deveria defender, como ... se houve o mensalão lá em Minas Gerais, se começou lá, o partido deveria ser o primeiro a colocar o dedo na cara, né? Entendeu? Agora não, não bota o dedo na ferida, começa a querer defender. Ahhh, pelo amor de Deus, aí não funciona.

Em outra manifestação, Miguel reforça a importância da honestidade na política, reafirmando o locus central de suas emoções em relação ao partido, em contraponto à ideia de desgosto ou descrédito. Ele reforça em seu depoimento o que Vigotski (1971) já afirmava que, ao aumentar a complexidade do elemento central de suas emoções, há uma redução da intensidade da sua ação, neste caso de sua participação política:

A minha vida inteira eu me pautei pela honestidade, tanto que fui secretário municipal ... E moro lá na Rua Fulano [nome fictício], e continuo morando lá, não tenho faxineira, não tenho isso, não tenho aquilo. Por quê? Honesto como fui a vida inteira. Agora, você é honesto com as coisas, vai trabalhar com um grupo de pessoas que não têm interesse, vamos dizer assim, não têm interesse realmente no Estado, na nação ... aí você se desencanta, sai fora, fala "não ... tô fora!".

É possível observar como a experiência de Miguel na política reforça o descrédito de todo o sistema para ele. Esta desconfiança com o sistema político, segundo Norris (2011), é uma evidência das mudanças sofridas pelo sujeito ao longo de sua trajetória, especialmente no sentido de aprimorar sua capacidade crítica. Nesse campo, é possível destacar, ainda, mais uma dimensão relevante na dinâmica das emoções dos sujeitos pesquisados, o orgulho.

\section{Orgulho em relação à atuação política}


As vivências presentes na experiência subjetiva dos sujeitos pesquisados evocam emoções de diferentes naturezas, como se verifica no relato de Miguel:

Agora, quando o Luiz Paulo se candidatou, eu atuei na campanha, subi morro com ele, desci morro. Nem tanto quanto eu queria, mas subi, porque ele me dava condição pra subir com ele, chegar com ele lá. Então, aí é aquela coisa assim: hoje é caminhada no morro tal.

Percebe-se o orgulho de Miguel na ação representada pelo excerto "chegar com ele lá", durante a campanha de Luiz Paulo para prefeito de Vitória. Essa emoção era suficiente, conforme ele, para motivá-lo a subir os morros da cidade acompanhando o candidato, chegando ao ponto de dizer que desejava fazê-lo com maior intensidade. Destaca-se, neste ponto, o fato de surgirem emoções contraditórias (descrédito com o sistema político versus o orgulho de participar) e que, aparentemente, atuam impulsionando a participação política de Miguel em direções opostas. Esse fenômeno evidencia a complexidade do processo de participação política através das emoções que estão em jogo.

Reafirma-se aqui que a emoção é uma produção imbricada na constituição social da subjetividade (Gomes \& Mello, 2010; González Rey, 2003; Pereira, Barros, \& Augusto, 2011), constituição esta que acontece, muitas vezes, nas contradições de seu cotidiano. Tais contradições podem ser observadas na constituição da participação de outro sujeito da pesquisa, Roberto, como se pode visualizar no trecho de uma de suas manifestações.

Uma pessoa, sem o sentimento da importância que a politica é, era pra ter desistido. As pessoas desistem por menos que isso, mas isso tá calçado na frase: a transformação da sociedade se dá através da política. E o cidadão não pode passar por essa vida sem deixar uma contribuição: tem pessoas que ajudam os pobres, tem pessoas que vai [sic] lá, sei lá, contribuem financeiramente, faz [sic] alguma, alguma, é [sic] maçom, outros têm outras instituições. Eu acho que a minha contribuição enquanto, só pra concluir, enquanto cidadão, para o futuro é a participação na politica.

Nota-se a esperança de transformação social por meio da política, acompanhada de uma crítica aos que desistem de participar politicamente por muito pouco. Identifica-se, ainda, que a solidariedade e a participação política, para Roberto, são necessidades. De acordo com González Rey (2003), é a partir da necessidade de participar que a participação política faz sentido para Roberto. A integração entre memória e avaliação (Vigotski, 1971; 2004), verificada no relato de Guilherme, também pode ser identificada em
Roberto, que se manifestou sobre o PSDB em relação a outros partidos: "O que diferencia o PSDB dos outros? Eu sei. Eu estudo isso. Você acha que todos são iguais? Não são iguais. Como os políticos não são iguais, os partidos também não são iguais. Defendem bandeiras". Identifica-se, ademais, o discurso que atribui à educação um lugar central em sua vida, com o objetivo de viabilizar o que seria, em sua visão, uma real participação política. A posição da educação na construção de sua participação é reforçada quando o dirigente abordado relata:

Fui a Cancun. Tudo pretexto. Eu não fui lá fazer política, fui aprender. Olha, eu li todos os livros do Fidel, tudo o que se falou sobre Fidel, eu li todos os livros sobre Che Guevara, todos os livros. Todos os melhores livros de Che Guevara, aliás, um mexicano, eu li essas coisas ... Isso tudo me interessa pra formação política.

O interesse de Roberto em investir na sua formação política pode estar, neste caso, relacionado a uma alegria em vivenciar tal processo de formação. Todavia, os aspectos emocionais como o orgulho, a vergonha ou a admiração estão presentes nos discursos de quem participa do partido político, o que nos permite compreender melhor os motivos que levam as pessoas a participarem politicamente de uma organização partidária como o PSDB.

\section{Considerações finais}

O presente artigo teve por objetivo compreender a dinâmica das emoções que envolvem a participação política de dirigentes do Partido da Social Democracia Brasileira no Espírito Santo - PSDB/ES. Observou-se o valor da honestidade, do sentimento de solidariedade, de pertencimento e de admiração integrando-se na mobilização dos recursos emocionais necessários à participação política nos diversos contextos em que os sujeitos transitam. A memória evocou sentimentos de admiração, de descrédito e de orgulho (Vigotski, 1971, 2004), e a experiência e a cognição dos dirigentes pesquisados evocaram as emoções de pertencimento, de solidariedade e de admiração. As emoções que afloraram nos depoimentos contribuíram para que os dirigentes estabelecessem juízo sobre as consequências de sua participação política.

As emoções que emergiram foram influenciadas pelos inúmeros aspectos aparentemente contraditórios dentro de uma teia de processos (González Rey, 2003). Nos momentos em que o grupo se reuniu, as emoções de tristeza e decepção com o PSDB contribuíam para reduzir a intensidade da participação política 
no partido. Estes sentimentos evocavam elementos subjetivos diferentes, que estavam em constante tensão com os sentimentos de solidariedade, honestidade e admiração (que marcavam a maior parte das emoções produzidas). González Rey (2003) defende que as emoções não estão limitadas ao intrapsíquico, já que se manifestam permanentemente, na dialética entre o indivíduo e a sociedade e, conforme se observou neste trabalho e que passou a fazer parte de um processo, ele mesmo dialético, dentro do qual cada dirigente constituía a sua participação.

Percebeu-se, ainda, o discurso que aponta para a necessidade de mudança das estruturas partidárias brasileiras de um modo geral. Um caminho interessante para tais mudanças seria a construção de uma estrutura que facilitasse a participação por meio de um maior envolvimento emocional dos dirigentes e militantes. Espera-se ainda que os partidos cumpram melhor o seu papel de promoção da participação democrática (Testi, 2000), negando o individualismo e o personalismo que ainda predominam em seu interior.

As emoções aqui identificadas podem contribuir para uma maior compreensão dos aspectos que levam ao (des) engajamento dos dirigentes partidários no PSDB. É possível observar que o sentimento de pertencimento ao partido conflita com as decepções sofridas ao longo da vivência partidária de cada um dos participantes da pesquisa. Assim, faz-se necessário repensar as práticas de tomada de decisão no partido, de modo a buscar maior envolvimento dos filiados.

Cumpre destacar que as falas obtidas em campo denotam emoções que emergem da experiência própria dos sujeitos, dinâmica que é influenciada por aspectos subjetivos inerentes a suas vivências particulares. Contudo, há que se considerar o contexto político brasileiro (em que se dão essas vivências), com o significativo distanciamento entre o sistema político formal e os cidadãos, entre representantes e representados (Sampaio, 2010). Tal fenômeno configura-se como algo histórico no Brasil, uma vez que, sendo a cultura política brasileira "fragmentada e de desconfiança" (Baquero, 2001, p. 99), nela, historicamente, estrutura-se uma mentalidade coletiva que privilegiaria o "distanciamento, o desencanto e a desconfiança generalizada" (Baquero, 2001, p. 99).

Embora o estudo seja limitado ao PSDB, as informações apresentadas podem ser relevantes para uma reflexão em termos gerais acerca das emoções envolvidas na participação política de dirigentes partidários ou mesmo de outros sujeitos envolvidos, nessa ou em outras organizações partidárias. Como recomendação para trabalhos futuros, caberia um aprofundamento nos elementos subjetivos dos espaços relacionais criados nos partidos políticos, sob o ponto de vista integrador da perspectiva histórico-cultural, ressaltando a importância de integrar as pessoas, dirigentes partidários ou não, aos espaços relacionais no seio do partido político.

Por fim, é possível afirmar que a política é uma instituição que marca formas de produção emocional nos cenários sociais (González Rey, 2004). Ela é socialmente produzida e reproduzida, de forma que se constroem normas e definem-se rumos. Entretanto, a dinâmica da dimensão emocional que envolve o fenômeno político encerra elementos altamente complexos, conforme demonstrado. Não obstante, conhecer as emoções envolvidas no processo de participação política, como o pertencimento, a admiração, o descrédito e o orgulho, além das significações implicadas nesse processo, é algo fundamental para avançar na compreensão do próprio fenômeno da participação política.

\section{Notas}

1 A figura da ave tucano é símbolo do partido, utilizado amplamente em suas campanhas de comunicação. Os integrantes do partido são, por isso, também chamados "tucanos".

2 O Governo do Estado do Espírito Santo viveu sua mais grave crise política e institucional durante o período em que foi comandado por José Ignácio Ferreira (1999-2002), que se elegeu pelo PSDB. As mazelas vivenciadas na época podem ser assim exemplificadas: governador ameaçado de impeachment, denúncias de cobrança de propina a empresas, Assembleia "sequestrando" o Executivo, prisões, escândalos de corrupção, desvios de dinheiro para campanhas, ameaça do crime organizado e pedido de intervenção federal (fonte: www.gazetaonline.com.br).

3 Yeda Crusius foi governadora do estado do Rio Grande do Sul entre 2007 e 2010, tendo sido acusada de participação no desvio de verbas do Detran. O caso ainda não foi julgado no Superior Tribunal de Justiça. Fonte: www.zerohora.com.br

\section{Referências}

Alves, D. S. \& Viscarra, S. (2012). Capital social, satisfação e as diferentes formas de participação política. Revista Debates, 6(1), 85-105.

Andaluiza, E. \& Bosch, A. (2009). El comportamiento político. In E. Andaluiza \& A. Bosch (Eds.), Comportamiento politico $y$ electoral (pp. 15-61). Barcelona: Editora Ariel.

Baquero, M. (2001). Cultura política participativa e desconsolidação democrática: reflexões sobre o Brasil contemporâneo. São Paulo Perspectiva, 15(4), 98-104.

Braga. M. S. S. (2008). Organizações partidárias e seleção de candidatos no Estado de São Paulo. Opinião Pública, 14(2), 454-485.

Castro, H. C. O. \& Reis, F. T. (2012). Participação política no Brasil no século XXI: mudanças e continuidades. Teoria \& Pesquisa: Revista de Ciência Politica, 21(2), 20-33. 
Duverger, M. (1963). Political parties. Londres: Science Editions.

Elster, J. (1998). Deliberative democracy. Cambridge: Cambridge University Press.

Gomes, C. A. V. \& Mello, S. A. (2010). Educação escolar e constituição do afetivo. Perspectiva, 28(2), 677-694.

González Rey, F. L. (2003). Sujeito e subjetividade: uma aproximação histórico-cultural. São Paulo: Pioneira Thomson Learning.

González Rey, F. L. (2004). O social na psicologia e a psicologia social: a emergência do sujeito. Petrópolis, RJ: Vozes.

González Rey, F. L. (2005). Pesquisa qualitativa e subjetividade: os processos de construção da informação. São Paulo: Pioneira Thomson Learning.

Ibañez, T. \& Iñiguez, L. (1996). El poder y los sistemas políticos. In J. Seoane \& A. Rodriguéz (Orgs.), Psicología política (pp. 331-358). Madrid: Editorial Síntesis.

Lamounier, B. (1992). Estrutura institucional e governabilidade na década de 1990. In J. P. R. Velloso (Org.), O Brasil e as reformas políticas (pp. 23-49). Rio de Janeiro: José Olympio.

Lamounier, B. (1994). A democracia brasileira de 1985 à década de 90: a síndrome da paralisia decisória. In J. P. R. Velloso (Org.), Governabilidade, sistema político e violência urbana (pp. 62-96). Rio de Janeiro: José Olympio.

Lima, O. B. (1993). Democracia e instituições políticas no Brasil dos anos 80. São Paulo: Loyola.

Meneguello, R. (1996). Partidos e tendências de comportamento: o cenário político em 1994. In E. Dagnino (Org.), Anos 90: política e sociedade no Brasil (pp. 151-172). São Paulo: Brasiliense.

Michels, R. (1949). Political parties. Nova Iorque: Free Press.

Norris, P. (2011). Democratic déficit: critical citizens revisited. Cambridge: Cambridge University Press.

Paiva, D., Braga, M. S. S., \& Pimentel, J. T. P. (2007). Eleitorado e partidos políticos no Brasil. Opinião pública, 13(2), 388408.

Pereira, T. T. S. O., Barros, M. N. S., \& Augusto, M. C. N. A. (2011). O cuidado em saúde: o paradigma biopsicossocial e a subjetividade em foco. Mental, $I X(17), 523-536$.

Russell, A. (2007). Political Parties as Vehicles of Political Engagement. Parliamentary affairs, 58(3), 555-569.

Sabucedo, J. M. C. (1996). Participación política. In J. M. C. Sabucedo (Ed.), Psicologia Política (pp. 85-97). Madri: Editorial Síntesis.

Sampaio, R. C. (2010). Participação política e os potenciais democráticos da internet. Debates, 4(1), 29-53.

Testi, A. (2000). Trionfo e declino dei partiti politici negli Stati Uniti, 1860-1930. Turin: Otto.

Verba, S. \& Nie, N. H. (1987). Participation in America. Chicago: University of Chicago Press.
Vigotski, L. S. (1971). The psychology of art. Massachussets: MIT Press.

Vigotski, L. S. (2004) Teoría de las emociones: estudio istóricopsicológico. Madri: Ediciones Akal.

\section{Agradecimentos}

À CAPES- bolsa Reuni, concedida ao primeiro autor 2011-12; à FAPES (taxa de pesquisa - processo 60057025/2012) e CNPQ (bolsa de produtividade processo 08376/2014-5).

Submissão em: 08/06/2014

Revisão em: 16/11/2014

Aceite em: 28/11/2014

Everton Faria Meira é mestre em Administração pela Universidade Federal do Espírito Santo. Endereço para correspondência: Rua Haylton Bassini Junior 51/501. Mata da Praia. Vitória/ES. CEP 29065440.

E-mail: evertonmeira@hotmail.com

Márcia Prezotti Palassi é doutora em Psicologia Social pela Pontifícia Universidde Católica de São Paulo PUC/SP. Professora do Programa de Pós-Graduação em Administração - PPGADM e do Programa de PósGraduação em Ciências Sociais - PPGCS da Universidade Federal do Espírito Santo. E-mail: mprezotti@hotmail.com

Alfredo Rodrigues Leite da Silva é doutor em Administração pela Universidade Federal de Minas Gerais - UFMG. Professor do Departamento de Administração e do Programa de Pós-Graduação em Administração da Universidade Federal do Espírito Santo - UFES. E-mail: alfredoufes@gmail.com

Letícia Dias Fantinel é doutora em Administração pela Universidade Federal da Bahia - UFBA. Professora do Departamento de Administração e do Programa de PósGraduação em Administração - PPGADM da Universidade Federal do Espírito Santo - UFES. E-mail: leticiafantinel@gmail.com 